\title{
Prognostic Significance of Amplitude-Integrated EEG during the First 72 Hours after Birth in Severely Asphyxiated Neonates
}

\author{
HENDRIK J. TER HORST, CONSTANZE SOMMER, KLASIEN A. BERGMAN, \\ JOHANNA M. FOCK, TIEMEN W. VAN WEERDEN, AND AREND F. BOS
} Department of Paediatrics [H.J.t.H., C.S., K.A.B., A.F.B.], Division of Neonatology, Beatrix Children's
Hospital, University Hospital, Hanzeplein 1, 9713 GZ Groningen, The Netherlands; and Department of
Neurology [J.M.F., T.W.v.W.], University Hospital, Hanzeplein 1, 9713 GZ Groningen, The Netherlands

\begin{abstract}
Amplitude-integrated EEG (aEEG) is used to select patients for neuroprotective therapy after perinatal asphyxia because of its prognostic accuracy within several hours after birth. We aimed to determine the natural course of aEEG patterns during the first $72 \mathrm{~h}$ of life, in relation to neurologic outcome, in a group of severely asphyxiated term infants. Thirty infants, admitted to our neonatal intensive care unit from October 1998 until February 2001, were studied retrospectively. The aEEG traces obtained during the first $72 \mathrm{~h}$ after birth were assessed by pattern recognition: continuous normal voltage (CNV), discontinuous normal voltage (DNV), burst suppression (BS), continuous low voltage, and flat trace. Epileptic activity was also determined. The course of aEEG patterns was examined in relation to neurologic findings at 24 mo. Initially, 17 of 30 infants had severely abnormal aEEG patterns (BS or worse), which changed spontaneously to normal voltage patterns (CNV, DNV) in 7 within $48 \mathrm{~h}$. The sooner the abnormalities on aEEG disappeared, the better the prognosis. The likelihood ratio of BS or worse for adverse outcome was 2.7 (95\% confidence interval 1.4-5.0) between 0 and $6 \mathrm{~h}$ and increased to a highest value of $19(95 \%$ confidence interval 2.8-128) between 24 and $36 \mathrm{~h}$; after $48 \mathrm{~h}$, it was not significant. Normal voltage patterns (CNV and DNV) up
\end{abstract}

\section{ABSTRACT}

to $48 \mathrm{~h}$ of life were predictive for normal neurologic outcomes (negative likelihood ratios $<0.3$ ). Our findings indicate that the course of aEEG patterns adds to the prognostic value of aEEG monitoring in asphyxiated infants. Spontaneous recovery of severely abnormal aEEG patterns is not uncommon. (Pediatr Res 55: 1026-1033, 2004)
Abbreviations
aEEG, amplitude-integrated EEG
BS, burst suppression
CI, confidence interval
CLV, continuous low voltage
CNV, continuous normal voltage
CNV-S, continuous normal voltage, with sleep stages
DNV, discontinuous normal voltage
EA, epileptic activity
FT, flat trace
LR-, negative likelihood ratio
$\mathbf{L R}+$, positive likelihood ratio
NICU, neonatal intensive care unit
SE, status epilepticus

Birth asphyxia is a major cause of perinatally acquired brain injury in full-term infants, accounting for $\sim 20-30 \%$ of all cases of cerebral palsy $(1,2)$. Several methods are used to assess the extent of neuronal damage during the first days and weeks of life. These include clinical signs (3), neuroimaging $(4,5)$, and neurophysiological techniques (6-9). During the first few

Received April 28, 2003; accepted January 22, 2004

Correspondence: Arend F. Bos, M.D., Ph.D., Department of Paediatrics, Division of Neonatology, Beatrix Children's Hospital, University Hospital, Hanzeplein 1, 9713 GZ Groningen, The Netherlands; e-mail: a.f.bos@bkk.azg.nl

This study is supported by the research program of the School of Behavioral and Cognitive Neurosciences, Groningen, the Netherlands.

Current address (C.S.): Karl Franzens University, Graz, Austria.

DOI: 10.1203/01.pdr.0000127019.52562.8c hours after birth, continuous amplitude-integrated EEG (aEEG) recorded with a cerebral function monitor is one of the most accurate bedside methods to establish neurologic prognosis in term asphyxiated infants $(10,11)$. The aEEG records a single-channel EEG from biparietal electrodes; frequencies $<2 \mathrm{~Hz}$ and $>15 \mathrm{~Hz}$ are filtered selectively, and the amplitude of the signal is integrated. The processed signal is recorded semilogarithmically onto a printer with a low paper speed (12). Previous studies have shown that aEEG correlates well with conventional EEG $(13,14)$.

Because of its prognostic accuracy very soon after perinatal asphyxia ( $80-85 \%$ within $6 \mathrm{~h}$ after birth), aEEG is the most suitable method to identify groups eligible for potentially neuroprotective treatments $(15)$, e.g. brain cooling $(16,17)$ and 
oxygen radical scavenging (18). There are, however, only a few studies that investigated the longitudinal course of aEEG tracings during the first few days after severe perinatal asphyxia in the absence of such interventions $(7,12)$. It therefore is necessary to obtain data on the "natural" course, i.e. without any neuroprotective intervention, of aEEG tracings in severely asphyxiated infants.

The aim of our study was to examine the prognostic accuracy of the course of aEEG tracings during the first $72 \mathrm{~h}$ after birth in a group of full-term infants who presented with severe perinatal asphyxia. Specific questions that we addressed were as follows: 1) Which longitudinal courses of aEEG recordings can be identified during the first $72 \mathrm{~h}$ in term infants after severe perinatal asphyxia? 2) What is the relationship of these courses with neurologic outcome at 2 y of age? 3) What is the role of conventional EEG in relation to aEEG recordings and neurologic outcome?

\section{METHODS}

\section{Patients}

We performed a retrospective cohort study. From our medical records, we identified all term infants (gestational age 37-42 wk) who were born between October 1998 and February 2001 and were admitted on the first day of life to the neonatal intensive care unit (NICU) of the University Hospital Groningen, the Netherlands, and treated for severe perinatal asphyxia. Severe asphyxia was defined if at least 2 of the following conditions were present: 1 ) signs of fetal distress (late decelerations on fetal heart rate monitoring or meconium staining of the amniotic fluid); 2) umbilical $\mathrm{pH}$ or first capillary $\mathrm{pH}$ (within 30 min after birth) $<7.00 ; 3$ ) delayed spontaneous respiration, necessitating artificial ventilation at $5 \mathrm{~min}$; and 4 ) signs of multiorgan failure.

Neonates with major congenital malformations and chromosomal abnormalities were excluded. The study was approved by the Institutional Review Board, and informed consent was obtained from the parents.

The cohort consisted of 39 infants. In four infants, aEEG recordings were not done, and in another four infants, the aEEG recordings lasted $<12 \mathrm{~h}$. One infant died at $19 \mathrm{~h}$ of age because of severe cardiac failure, and he was also excluded from further analysis. As a result, the study population consisted of 30 infants for whom reliable aEEG recordings had been performed continuing after $24 \mathrm{~h}$ of age.

Clinical data of the study population are shown in Table 1. Most of the infants were outborn. Birth weights ranged from 2200 to $4445 \mathrm{~g}$ (median $3485 \mathrm{~g}$ ), Apgar scores at $1 \mathrm{~min}$ were from 0 to 6 (median 1) and at 5 min were from 0 to 8 (median 4). Two infants had birth weights below the fifth centile. Initial $\mathrm{pH}$ values ranged from 6.65 to 7.22 (median 6.86) with base excess from -32 to -11.6 (median -22.1 ). From the medical records, we obtained additional data on the obstetric history, stage of encephalopathy according to Sarnat and Sarnat (3) at $24 \mathrm{~h}$ of age, presence of seizures and antiepileptic treatment, and neuroimaging data. Although not an entry criterion for the study, all infants had at least mild encephalopathy, stage I. In three infants, the stage of encephalopathy could not be assessed because of the use of paralyzing agents (Table 1). Clinical seizures occurred in 23 infants, in 17 infants already before the aEEG recording had been started. All infants with clinical seizures were treated with antiepileptic drugs (phenobarbital as drug of first choice). During aEEG recording, clinical seizures occurred in 11 infants, 6 of whom had not yet received antiepileptic drugs.

Eight infants died in the neonatal period. Follow-up of the other infants was regularly performed at the outpatient clinic and consisted of a pediatric and a neurologic examination, based on Touwen (19). The pediatricians involved in the follow-up of our NICU infants were not aware of the aEEG findings. Follow-up data are available on all infants at the age of $24 \mathrm{mo}$. The neurologic findings were classified as normal, severely abnormal (severe mental and motor delay, infantile spasms, or cerebral palsy according to the criteria of Hagberg et al. (20)), and mildly abnormal (neurologic abnormalities present, other than cerebral palsy or infantile spasms, e.g. gross motor abnormalities, coordination problems, epilepsy, or hearing deficits).

\section{Assessment of aEEG Recordings}

Recording of the aEEG (Cerebral Function Monitor 4640; Lectromed, Ltd., Letchworth, UK) was started immediately after admission, at a median age of $4 \mathrm{~h} 35 \mathrm{~min}$ after birth (range $60 \mathrm{~min}-22 \mathrm{~h}$ ). The median duration of aEEG recordings during the first $72 \mathrm{~h}$ after birth was $44 \mathrm{~h} 33 \mathrm{~min}(12 \mathrm{~h} 30 \mathrm{~min}-68 \mathrm{~h}$ ). The aEEG was recorded from biparietal needle electrodes and displayed on the integral printer at $6 \mathrm{~cm} / \mathrm{h}$. The impedance between electrodes was also recorded and was always below 5 $\mathrm{k} \Omega$. Handling of the infant, observed clinical seizures, and administration of anticonvulsant or sedative drugs were recorded by the nursing staff.

We analyzed the aEEG using pattern recognition according to the definitions given by Toet et al. (11):

Continuous normal voltage with cycling of sleep stages $(\boldsymbol{C N V}-\mathrm{S})$. Continuous background activity with voltage $10-25$ $(-50) \mu \mathrm{V}$, with the band of aEEG activity altering in width, indicating cycling of sleep stages (21).

Continuous normal voltage (CNV). Continuous background activity with voltage $10-25(-50) \mu \mathrm{V}$ but without sleep stages.

Discontinuous normal voltage (DNV). Discontinuous trace, with voltage predominantly $>5 \mu \mathrm{V}$.

Burst suppression (BS). Discontinuous trace with periods of very low cortical activity $(<5 \mu \mathrm{V})$, intermixed with bursts of higher amplitude.

Continuous low voltage (CLV). Continuous background pattern of very low voltage (around or below $5 \mu \mathrm{V}$ ).

Flat tracing (FT). Mainly inactive (isoelectric tracing) of extremely low voltage $(<5 \mu \mathrm{V})$.

Epileptic activity was also identified:

Epileptic activity (EA). Single or repetitive events (at a frequency of less than once per hour), with sudden sustained cortical activity.

Status epilepticus (SE). Repeated EA, resulting in a regular pattern of increased cortical activity (sawtooth pattern). 


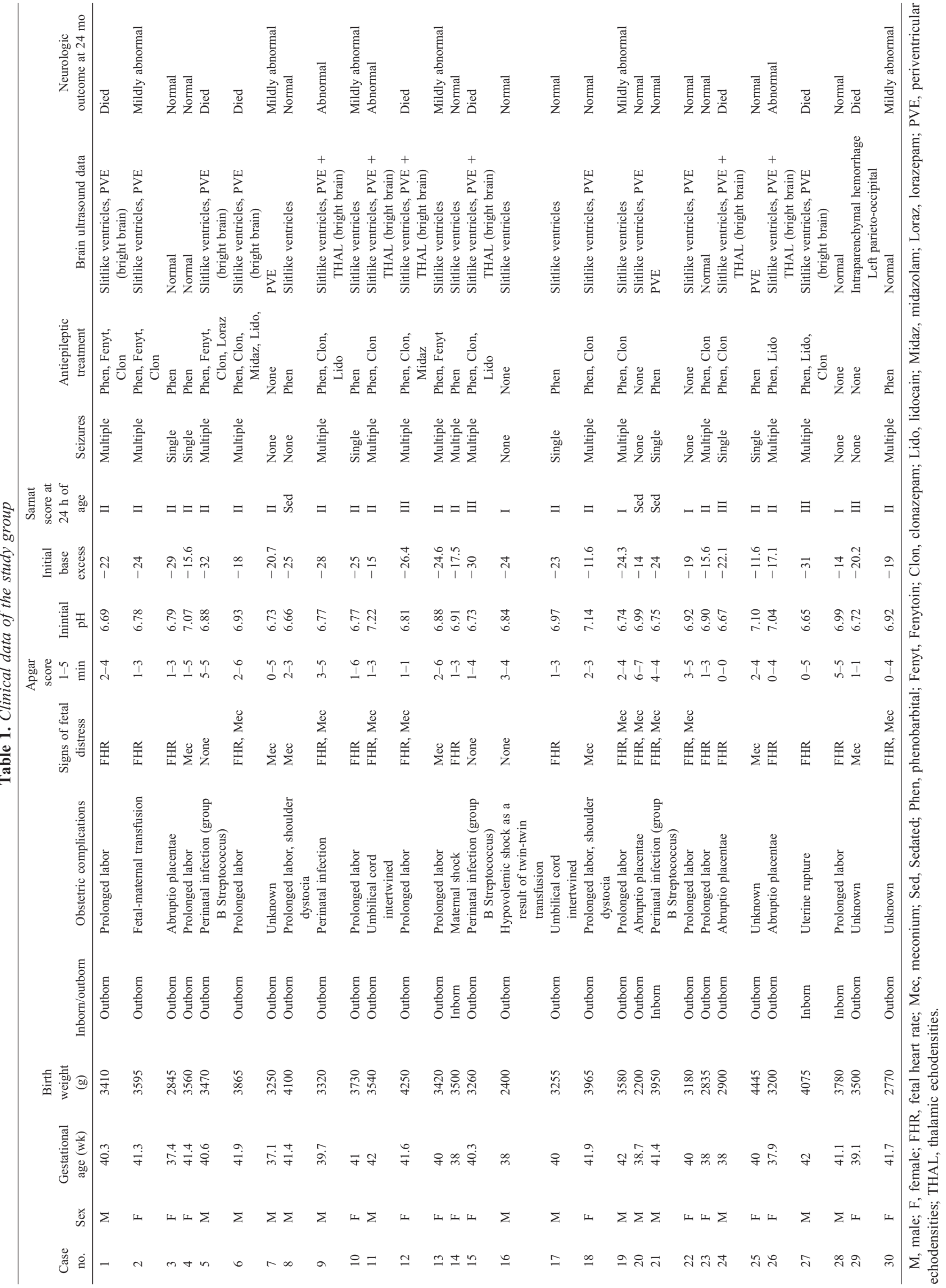


A CNV pattern was considered as normal, DNV as mildly abnormal, and all others as severely abnormal. Examples of the various aEEG patterns are shown in Fig. 1.

All traces were analyzed off line by three investigators (H.t.H., C.S., A.F.B.), who were blinded to neurologic outcome. It included an assessment of the background pattern, including epileptic status, and, if present, transitions from one pattern to another. A transition was regarded as such when the new pattern had lasted at least $30 \mathrm{~min}$. The presence of isolated events of EA was also noted. Artifacts were excluded unless they were very short lasting and the aEEG pattern before the artifact was similar to the pattern afterward. Agreement about the specific type of aEEG pattern was reached in $88 \%$ of cases $(\kappa=0.85)$.
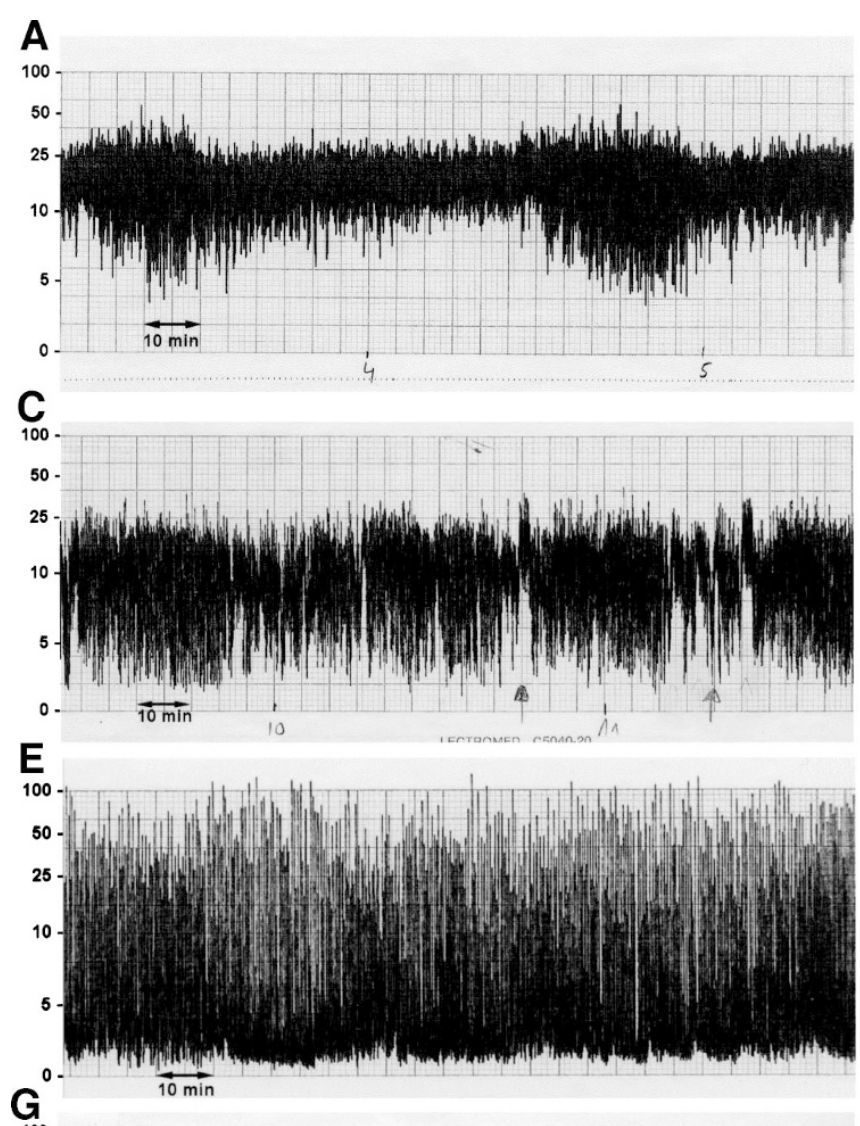

$\mathbf{F}$

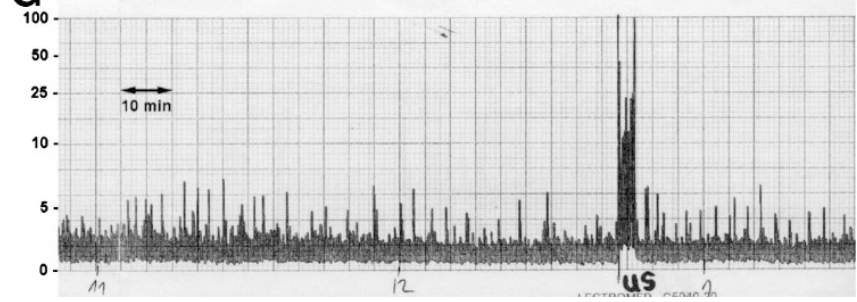

The sequence of patterns of each individual infant was graphically displayed on the time axis for the first $72 \mathrm{~h}$ of life, with the time of birth as $t=0$. In this way, individual longitudinal sequences of aEEG patterns were obtained from each infant. Next, the longitudinal sequences of aEEG patterns were grouped according to neurologic outcome.

In 24 cases, a conventional EEG (20 electrodes, duration $1 \mathrm{~h}$ ) was obtained between 12 and $48 \mathrm{~h}$ of life, simultaneous with recording of the aEEG. One clinical neurophysiologist (T.v.W.), who was unaware of the aEEG findings and was experienced in interpreting neonatal EEG, assessed all EEGs. The background pattern of the EEG was classified as normal, discontinuous, suppression burst, low voltage, and isoelectric (22). In addition, presence and location of epileptic discharges
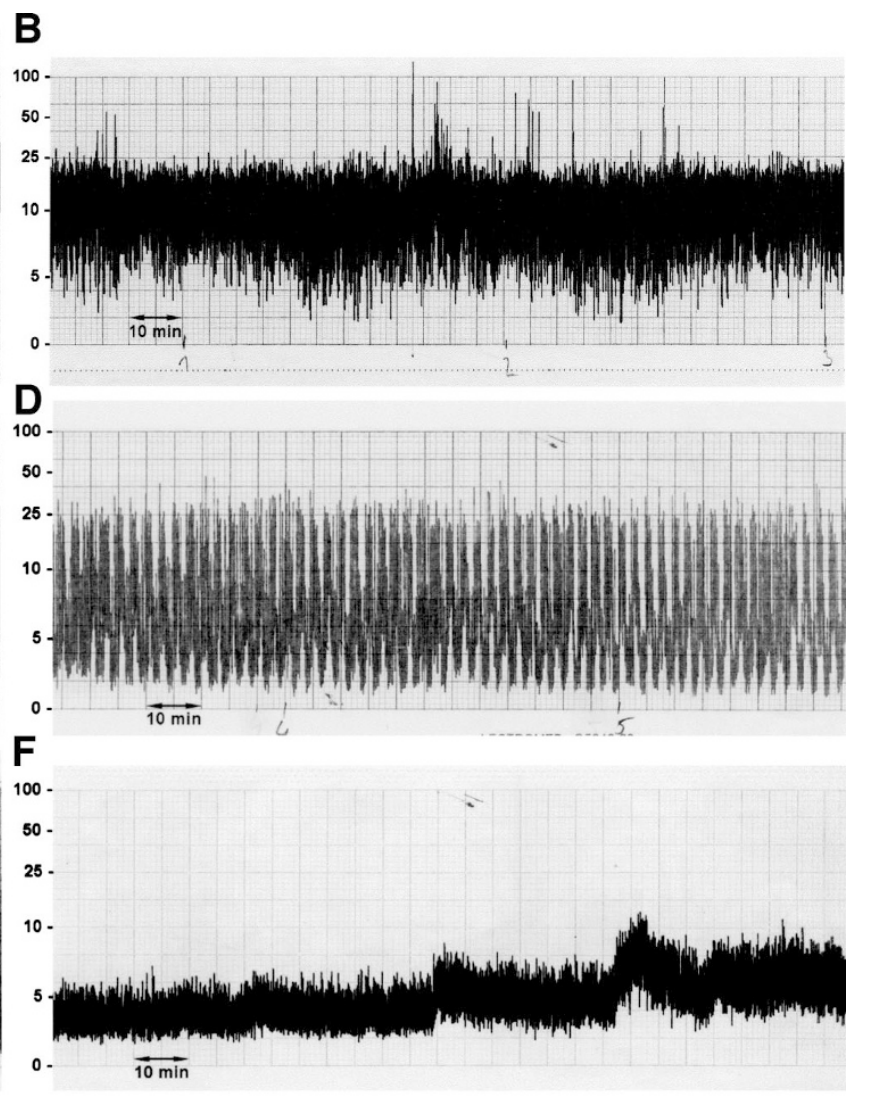

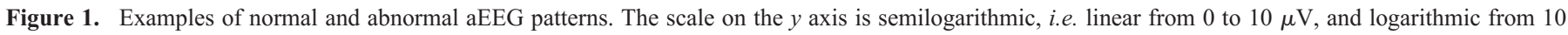

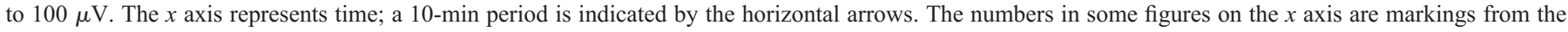

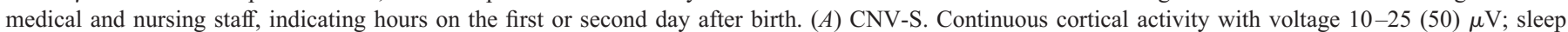

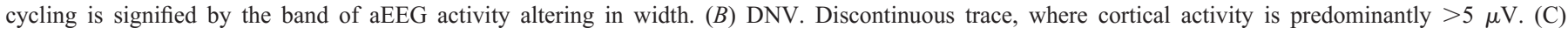

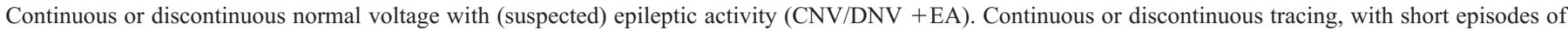

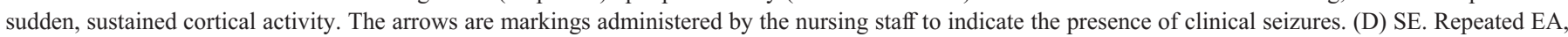

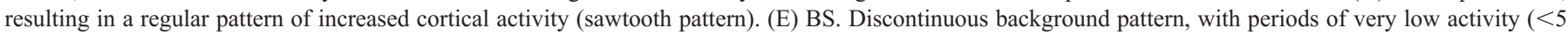

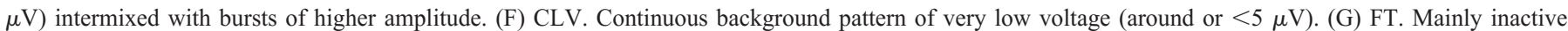

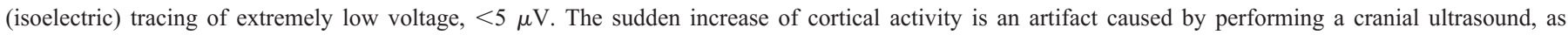
indicated by "US," administered by the nursing staff. 
were noted. Spike waves were classified as epileptic discharges. Spikes and sharp waves were considered to be epileptic when there was a repetitive character or when they showed a persistent focality. Sharp transients were not noted as an epileptic phenomenon. The findings on conventional EEG were compared with the findings on the aEEG trace, with respect to background patterns and presence of epileptic phenomena.

Statistical analysis. For testing the correlation between the degree of abnormality of the aEEG patterns and neurologic outcome, the Spearman rank order correlation coefficient was calculated and two-tailed tested. Positive (LR +$)$ and negative likelihood ratios (LR-) were calculated to assess the predictive value of abnormal and normal aEEG traces for neurologic outcome. A $p<0.05$ was considered statistically significant.

\section{RESULTS}

Longitudinal course of aEEG patterns. Seventeen infants had severely abnormal aEEG patterns at admission. Fourteen were admitted before $12 \mathrm{~h}$ after birth. In five of them, the aEEG improved to normal voltage patterns $(\mathrm{CNV}, \mathrm{DNV})$ within $12 \mathrm{~h}$ after birth; in two, it improved between 24 and $48 \mathrm{~h}$ after birth. In 10 infants, the aEEG patterns remained severely abnormal throughout the first $72 \mathrm{~h}$ of life or until death, although the degree of abnormality changed in three of them from lowvoltage patterns to BS.

Thirteen infants had normal (CNV, $n=6)$ or mildly abnormal (DNV, $n=7$ ) aEEG traces at admission. In these infants, all traces remained of normal voltage, except for two infants. In one infant, a short period of BS occurred between 24 and $36 \mathrm{~h}$ after birth; in the other infant, EA was obvious at $\sim 72 \mathrm{~h}$ after birth.

Epileptic activity on aEEG. In the total group, EA was recognized on 10 aEEG traces, either as isolated events or as epileptic status. In two of these infants, the electrographic EA was not clinically evident at all, and in four, it continued or returned electrographically after apparently successful treatment of the clinical manifestations. Suspicious clinical signs suggestive of seizures that could not be recognized on the aEEG traces occurred in four infants. All infants with either clinical or silent seizures were treated with antiepileptic drugs. Treatment with antiepileptic drugs never changed a normal pattern into a severely abnormal one, although in some infants, the pattern became transiently more discontinuous than before, for $\sim 30$ to $60 \mathrm{~min}$.

The course of aEEG patterns in relation to neurologic findings at $2 y$. Figure 2 displays the longitudinal course of aEEG patterns recorded during the first $72 \mathrm{~h}$ after birth of all infants, grouped according to neurologic outcome. Thirteen infants were normal at follow-up. All except four showed aEEG traces with normal voltage patterns (DNV, CNV, CNVS). Three infants had short periods of BS, and one infant had even a short period of low-voltage trace (FT and CLV) at $\sim 6 \mathrm{~h}$ after birth. All improved spontaneously to a normal voltage pattern (DNV, CNV, CNV-S) within the first $12 \mathrm{~h}$ after birth.

Six infants had mild neurologic deficits at follow-up. Their aEEG traces showed predominantly normal voltage patterns

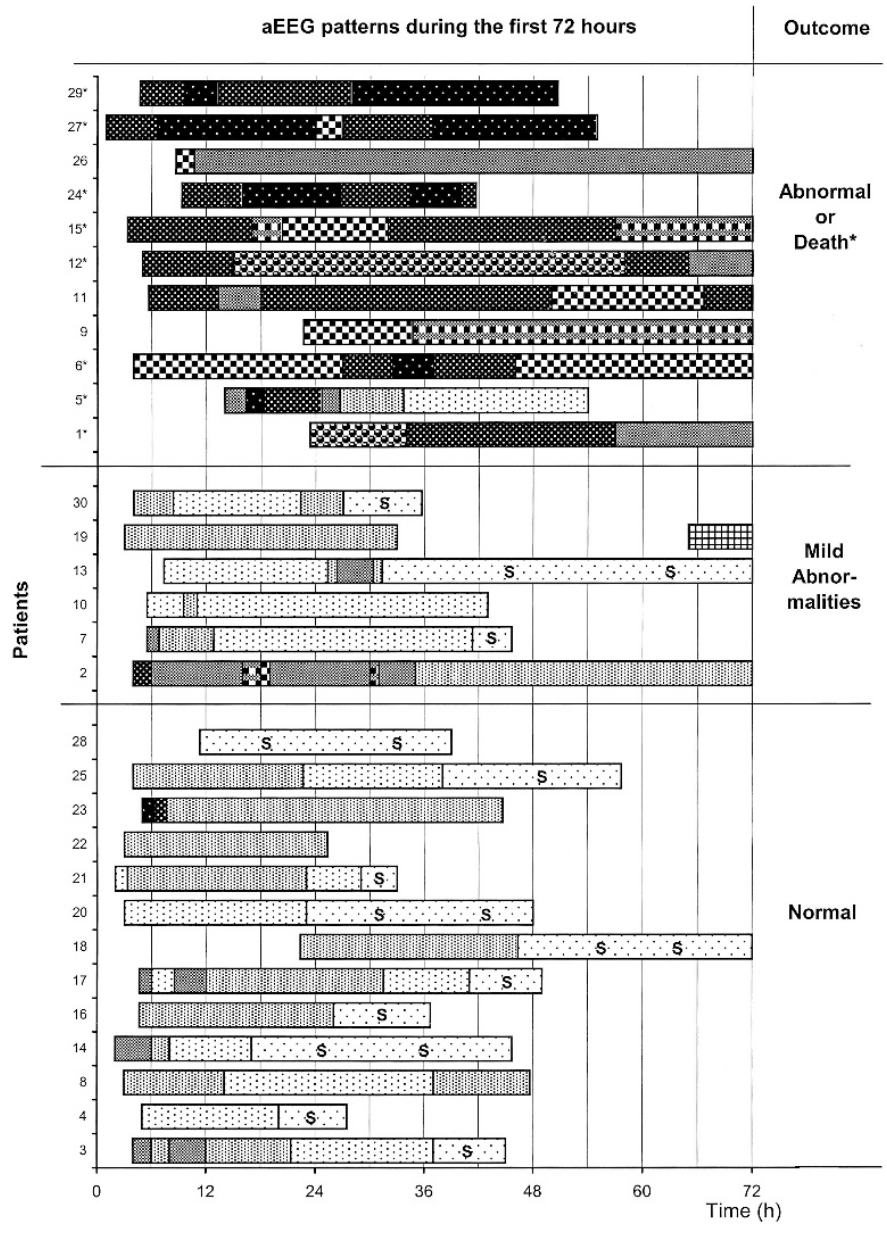

Figure 2. Longitudinal course of aEEG patterns in 30 term asphyxiated neonates, during the first $72 \mathrm{~h}$ of life, grouped according to their neurologic

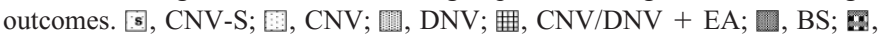
$\mathrm{BS}+\mathrm{EA} ; \boldsymbol{\otimes}, \mathrm{SE} ; \mathrm{CLV} ; \mathrm{M}, \mathrm{CLV}+\mathrm{EA} ; \mathbf{\mathrm { N }}, \mathrm{FT}$.

(DNV, CNV, CNV-S) as well. Two infants had additionally short periods of BS, one of them during the first $12 \mathrm{~h}$ after birth and the other between 24 and $48 \mathrm{~h}$ after birth. Another infant had a low-voltage pattern (CLV) followed by a long period of BS up to $36 \mathrm{~h}$ after birth, intermixed with short periods of clinical seizures and EA on aEEG. Finally, one neonate initially had a DNV trace but got clinical seizures and EA on the aEEG on the third day of life.

Three infants had severe neurologic deficits at follow-up, and eight infants died. All but one had severely abnormal aEEG patterns (BS, CLV, FT) throughout the first $72 \mathrm{~h}$ after birth. Eight of them had in addition episodes of epileptic status $(n=6)$ or EA superimposed on CLV $(n=2)$.

Prognostic value of aEEG patterns for neurologic outcome at $2 y$. A strong correlation existed between the sequence of normal and severely abnormal aEEG patterns and neurologic findings at follow-up (Table 2). The sooner the abnormal aEEG patterns normalized, the better the prognosis. Persistent abnormal aEEG patterns were predictive of severe deficits or death. The cut-off point was between 12 and $48 \mathrm{~h}$ after birth (Table 3 ). Patterns showing BS or worse had, if present before $6 \mathrm{~h}$ of age, a LR+ of 2.7 [95\% confidence interval (CI) 1.4-5.0] for adverse outcome; it increased to a highest value of 19 (95\% CI 
Table 2. Correlation between the course of aEEG patterns and neurologic outcome (only infants recorded within $12 \mathrm{~h}$ were included)

\begin{tabular}{lccc}
\hline & \multicolumn{2}{c}{ Neurologic outcome at 24 mo } \\
\cline { 2 - 4 } aEEG patterns & Normal & $\begin{array}{c}\text { Mild } \\
\text { deficits }\end{array}$ & $\begin{array}{c}\text { Severe deficits } \\
\text { or deceased }\end{array}$ \\
\hline Only DNV/CNV, including cycling of sleep stages & 6 & 1 & 7 \\
Only DNV/CNV, no sleep stages & 2 & 1 & 3 \\
DNV/CNV $\rightarrow$ BS/EA $(\rightarrow$ DNV/CNV) & & 2 & 5 \\
FT/BS/EA $\rightarrow$ DNV/CNV before 12 h of age & 4 & 1 & 8 \\
FT/BS/EA $\rightarrow$ DNV/CNV before 36 h of age & & 1 & 8 \\
Persistent FT/CLV/SE/BS & 12 & 6 & 8 \\
Total & & 26 \\
\hline
\end{tabular}

Spearman correlation coefficient: $r=0.792 ; p<0.001$ (two-tailed).

The arrow $(\rightarrow)$ marks a transition from one pattern to another.

Table 3. $L R+$ and $L R-(95 \%$ CI) for abnormal aEEG patterns (BS or worse) from birth to $72 \mathrm{~h}$ of age as predictive test for severe neurologic abnormalities at 2 y of age

\begin{tabular}{lccc}
\hline & \multicolumn{2}{c}{$\mathrm{LR}+$ and LR $-(95 \% \mathrm{CI})$} & \\
Postnatal age & $\mathrm{LR}+$ & $<0.3$ & 22 \\
\hline $0-6 \mathrm{~h}$ & $2.7(1.4-5.0)$ & $<0.2$ & 26 \\
$6-12 \mathrm{~h}$ & $3.6(1.7-7.6)$ & $<0.1$ & 30 \\
$12-24 \mathrm{~h}$ & $19.0(2.8-128)$ & $<0.1$ & 30 \\
$24-36 \mathrm{~h}$ & $9.5(2.6-35)$ & $0.09(0.01-0.59)$ & 24 \\
$36-48 \mathrm{~h}$ & $>11$ & $0.15(0.02-1.0)$ & 13 \\
$48-72 \mathrm{~h}$ & $3.6(0.64-20)$ & & \\
\hline
\end{tabular}

$2.8-128$ ) between 24 and $36 \mathrm{~h}$; after $48 \mathrm{~h}$, it was not significant anymore. Normal voltage aEEG patterns $(\mathrm{CNV}, \mathrm{DNV})$ had $\mathrm{LR}-$ for severe neurologic deficits at follow-up $<0.3$, throughout the first $48 \mathrm{~h}$ of life.

aEEG patterns did not differentiate between normal and mild deficits at follow-up. Of this group of 19 infants, only 3 had exclusively CNV patterns; all developed normally. Sixteen infants had mildly abnormal aEEG patterns (DNV) or worse for at least some period of the study. Normalization toward $\mathrm{CNV}$ and duration of these mildly abnormal traces were not different between groups. Severely abnormal patterns (BS or worse) were observed in seven infants, four of whom developed normally. Their aEEG patterns improved to CNV or DNV before $12 \mathrm{~h}$ of age. Improvement toward CNV or DNV occurred slightly later, between 24 and $36 \mathrm{~h}$, in two of three infants with mild deficits. Cycling of sleep stages occurred in 10 of 13 later normal infants (median onset $28.5 \mathrm{~h}$ after birth), compared with 3 of 6 later mildly abnormal infants (median onset $32 \mathrm{~h}$ after birth). None of these differences reached statistical significance. Absence of sleep cycling in case of normal voltage aEEG patterns was also not predictive for mild deficits $(\mathrm{LR}+2.2,95 \%$ CI $0.6-7.8 ; \mathrm{LR}-0.7,95 \% \mathrm{CI}$ $0.3-1.5)$.

Conventional EEG in relation to aEEG and neurologic outcome. Conventional EEG was performed in 24 infants between 12 and $48 \mathrm{~h}$ of life. In the six infants for whom it was not performed, aEEG traces were exclusively CNV or DNV and neurologic outcome was normal. In the remaining infants, agreement of the type of background pattern between EEG and aEEG was $83 \%(\kappa=0.79)$. Disagreement was diverse: one infant had CNV on aEEG, with a discontinuous background pattern on conventional EEG; one had DNV on aEEG, with a normal background pattern on EEG. Two infants had CLV on
aEEG, whereas conventional EEG was judged as $\mathrm{BS}$ in the one and isoelectric trace in the other.

Two infants had epileptic status/repetitive EA on aEEG that was confirmed by conventional EEG. In infants with normal voltage background activity, 2 of 12 had focal EA on conventional EEG, which was not identified on aEEG. At follow-up, one of those infants had mild neurologic deficits and one was normal.

\section{DISCUSSION}

The present study indicates that the natural course of aEEG patterns in term asphyxiated infants can be very diverse. Despite the profound severity of asphyxia, $40-50 \%$ of infants had normal voltage aEEG patterns shortly after birth, even though it was discontinuous in the majority of infants. In those who presented with severely abnormal aEEG patterns, spontaneous recovery within $12 \mathrm{~h}$ toward normal voltage traces occurred in approximately one third of infants. Our data are in line with previous studies on conventional EEG showing that normalization of abnormal background patterns is not uncommon during the first day of life and associated with normal neurologic outcomes (22-24). Future studies investigating neuroprotective strategies should take this rate of spontaneous recovery into account.

Apart from asphyxia, antiepileptic drugs may have contributed to the discontinuity of the EEG $(8,25)$. Previous studies have shown that this might occur in a small number of infants $(7,11)$. However, the suppressive effects of antiepileptic drugs on aEEG in most studies is reported as relatively short lasting, several hours at most (10), or absent (12). In the present study, none of the infants with normal voltage patterns developed severely abnormal patterns after antiepileptic treatment.

We found that aEEG at an early age differentiates very well between infants with later severe neurologic deficits and infants with mild deficits or normal outcomes. When aEEG background patterns were of normal voltage (CNV, DNV) or normalized before the age of $24 \mathrm{~h}$, prognosis was fair, whereas severely abnormal aEEG patterns that persisted beyond that age were related to adverse outcomes. Previous studies have shown that, already several hours after birth, aEEG recording is a reliable method for early prediction of neurologic outcome in asphyxiated infants, with accuracy between 70 and $85 \%(8$, $11,12,26)$. Our findings indicate that extension of the recording period up to $48 \mathrm{~h}$ after birth adds to the prognostic value. 
We were not able to detect a particular course of aEEG patterns that differentiated between normal infants and infants with later mild deficits. Severely abnormal aEEG patterns, if present at all, tended to improve slightly later in the group of infants with mild deficits, between 24 and $36 \mathrm{~h}$ instead of before $12 \mathrm{~h}$ of age. However, the number of infants in this subgroup is too small to provide conclusive evidence in this respect. Normal (CNV) and mildly abnormal (DNV) aEEG patterns were predominant in both groups of infants, similar to what has been reported before (11). Neither the presence of DNV patterns nor the age at which improvement of DNV into $\mathrm{CNV}$ occurred was different between groups. Presence or emergence of sleep stages also did not have any prognostic value. It must be noted that follow-up is relatively short, and it might be that neurologic or developmental abnormalities appear later in life.

We included death and severe neurologic abnormalities as a single outcome group. For determining the prognostic value of aEEG recordings, it is a practical classification, but it might be incorrect if clinical decisions to discontinue intensive care treatment were made on the basis of aEEG recordings. Decisions that intensive care treatment is not appropriate should not be based on a single test but rather after thorough investigations and repeated clinical examinations and discussions between professionals have taken place and with consent of adequately informed parents. The close relation among the aEEG recordings, the conventional EEG findings, and the clinical and the neuroimaging data in both survivors and nonsurvivors of the poor outcome group indicate that discontinuing intensive care is unlikely to have biased our findings.

In this group of asphyxiated infants, $60 \%$ of the infants had suspicion of single or multiple clinical seizures and were treated with antiepileptic drugs. After treatment, aEEG patterns of several infants still revealed repeated EA, even epileptic status, which was clinically not obvious in several infants. It is widely known that electrographic discharges do not necessarily result in clinical seizures, before and after antiepileptic treatment (27). From previous studies, it is estimated that $>50 \%$ of seizures identified on EEG or aEEG in newborn infants may be silent (28-30). There is considerable controversy over whether silent seizures in infants with hypoxic-ischemic encephalopathy lead to damage of the developing brain and should be treated (31). It might be argued that epileptic discharges in this setting are a consequence of damage that is already present, and therefore antiepileptic treatment will not influence later outcome. In addition, several antiepileptic drugs administered in the perinatal period even induce neuronal apoptosis (32). Conversely, animal and human data indicate that seizures in the developing brain may be harmful, at least in the short term, considering disturbances in cerebral blood flow, energy metabolism, and excitotoxic amino acids (33-36). Data on long-term follow-up, however, are lacking. Further studies are required to elucidate this controversy and to optimize treatment in this respect.

There was a good agreement between conventional EEG and aEEG recordings, similar to previous studies $(8,12,14)$. Conventional EEG provided additional information in only two infants, showing focal EA that was not identified on aEEG.
In general, seizure activity is well recognized on aEEG (26, 37 ). It is widely known, however, that focal and short-lasting electrographic seizure activity $(<30 \mathrm{~s})$ is not detected by aEEG $(14,38)$.

The advantages of continuous aEEG recording in a NICU setting are many-fold. Interpretation is easy and can be learned by nurses, junior medical staff, and neonatologists after a short period of training. It reveals background patterns and their changes, including epileptic status and (repetitive) electrographic seizures lasting $>30 \mathrm{~s}$. It is useful as a monitoring and screening device for prolonged periods. We used needle electrodes, which were well tolerated without causing any harm. Similar to al Naqeeb et al. (26), we did not observe any complications related to its use. It is possible to perform a conventional EEG simultaneously. Thus, the aEEG may serve well as a screening test, and a conventional EEG can be performed on detection of abnormalities.

\section{CONCLUSION}

In conclusion, the present study confirms the prognostic accuracy of aEEG patterns shortly after birth in term asphyxiated infants. Our findings indicate that the course of aEEG patterns during the first $48 \mathrm{~h}$ after birth adds to the prognostic value of aEEG monitoring. Spontaneous recovery of severely abnormal aEEG patterns is not uncommon. The sooner the abnormalities on aEEG disappear, the better the prognosis.

\section{REFERENCES}

1. Hagberg B, Hagberg G, Beckung E, Uvebrant P 2001 Changing panorama of cerebral palsy in Sweden. VIII. Prevalence and origin in the birth year period 1991-94. Acta Paediatr 90:271-277

2. Volpe JJ 2001 Neurology of the Newborn. W.B. Saunders Company, Philadelphia, pp 283-284

3. Sarnat HB, Sarnat MS 1976 Neonatal encephalopathy following fetal distress. Arch Neurol 33:696-705

4. Biagioni E, Mercuri E, Rutherford M, Cowan F, Azzopardi D, Frisone MF, Cioni G, Dubowitz L 2001 Combined use of electroencephalogram and magnetic resonance imaging in full-term neonates with acute encephalopathy. Pediatrics 107:461-468

5. Rutherford MA, Pennock JM, Counsell SJ, Mercuri E, Cowan F, Dubowitz LMS, Edwards AD 1998 Abnormal magnetic resonance signal in the internal capsule predicts poor neurodevelopmental outcome in infants with hypoxic-ischemic encephalopathy. Pediatrics 102:323-328

6. Monod N, Pajot N, Guidasci S 1972 The neonatal EEG: statistical studies and prognostic value in full-term and pre-term babies. Electroencephalogr Clin Neurophysiol 32:529-544

7. Thornberg E, Ekstrom-Jodal B 1994 Cerebral function monitoring: a method of predicting outcome in term neonates after severe perinatal asphyxia. Acta Paediatr 83:596-601

8. Hellström-Westas L, Rosen I, Svenningsen NW 1995 Predictive value of early continuous amplitude integrated EEG recordings on outcome after severe birth asphyxia in full term infants. Arch Dis Child Fetal Neonatal Ed 72:F34-F38

9. Selton D, André M 1997 Prognosis of hypoxic-ischaemic encephalopathy in full-term newborns - value of neonatal electroencephalography. Neuropediatrics 28:276-280

10. Eken P, Toet MC, Groenendaal F, de Vries LS 1995 Predictive value of early neuroimaging, pulsed Doppler and neurophysiology in full term infants with hypoxicischaemic encephalopathy. Arch Dis Child Fetal Neonatal Ed 73:F75-F80

11. Toet MC, Hellström-Westas L, Groenendaal F, Eken P, de Vries LS 1999 Amplitude integrated EEG 3 and 6 hours after birth in full term neonates with hypoxic-ischaemic encephalopathy. Arch Dis Child Fetal Neonatal Ed 81:F19-F23

12. Bjerre I, Hellström-Westas L, Rosen I, Svenningsen NW 1983 Monitoring of cerebral function after severe asphyxia in infancy. Arch Dis Child 58:997-1002

13. Hellström-Westas L 1992 Comparison between tape-recorded and amplitudeintegrated EEG monitoring in sick newborn infants. Acta Paediatr 81:812-819

14. Toet MC, van der Mei W, de Vries LS, Uiterwaal CSPM, van Huffelen AC 2002 Comparison between simultaneously recorded amplitude integrated electroencephalogram (cerebral function monitor) and standard electroencephalogram in neonates. Pediatrics 109:772-779

15. Groenendaal F, de Vries LS 2000 Selection of babies for intervention after birth asphyxia. Semin Neonatol 5:17-32 
16. Azzopardi D, Robertson NJ, Cowan FM, Rutherford MA, Rampling M, Edwards AD 2000 Pilot study of treatment with whole body hypothermia for neonatal encephalopathy. Pediatrics 106:684-694

17. Whitelaw A, Thoresen M 2001 Clinical experience with therapeutic hypothermia in asphyxiated infants. Dev Med Child Neurol Suppl 86:30-31

18. Van Bel F, Shadid M, Moison RMW, Dorrepaal CA, Fontijn J, Monteiro L, van de Bor M, Berger HM 1998 Effect of allopurinol on postasphyxial free radical formation, cerebral hemodynamics, and electrical brain activity. Pediatrics 101:185-193

19. Touwen BCL 1976 Neurological Development in Infancy. William Heinemann Medical Books Ltd., London, pp 17-150

20. Hagberg B, Hagberg G, Olow I 1975 The changing panorama of cerebral palsy in Sweden1954-1970: I. Analysis of the general changes. Acta Paediatr Scand 64:187192

21. Thornberg E, Thiringer K 1990 Normal pattern of the cerebral function monitor trace in term and preterm neonates. Acta Paediatr Scand 79:20-25

22. Pressler RM, Boylan GB, Morton M, Binnie CD, Rennie JM 2001 Early serial EEG in hypoxic ischaemic encephalopathy. Clin Neurophysiol 112:31-37

23. Azzopardi D, Guarino I, Brayshaw C, Cowan F, Price-Williams D, Edwards AD, Acolet D 1999 Prediction of neurological outcome after birth asphyxia from early continuous two-channel electroencephalography. Early Hum Dev 55:113-123

24. Zeinstra E, Fock JM, Begeer JH, van Weerden TW, Maurits NM, Zweens MJ 2002 The prognostic value of serial EEG recordings following acute neonatal asphyxia in full-term infants. Eur J Paediatr Neurol 5:155-160

25. Biagioni E, Bartalena L, Boldrini A, Pieri R, Cioni G 1999 Constantly discontinuous EEG patterns in full-term neonates with hypoxic-ischaemic encephalopathy. Clin Neurophysiol 110:1510-1515

26. al Naqeeb N, Edwards AD, Cowan FM, Azzopardi D 1999 Assessment of neonata encephalopathy by amplitude-integrated electroencephalography. Pediatrics 103:1263-1271

27. McBride MC, Laroia N, Guillet R 2000 Electrographic seizures in neonates correlate with poor neurodevelopmental outcome. Neurology 55:506-513
28. Hellström-Westas L, Rosen I, Swenningsen NW 1985 Silent seizures in sick infants in early life. Diagnosis by continuous cerebral function monitoring. Acta Paediat Scand 74:741-748

29. Clancy RR, Legido A, Lewis D 1988 Occult neonatal seizures. Epilepsia 29:256-261

30. Pinto LC, Giliberti P 2001 Neonatal seizures: background EEG activity and the electroclinical correlation in full-term neonates with hypoxic-ischemic encephalopathy. Analysis by computer-synchronized long-term polygraphic video-EEG monitoring. Epileptic Disord 3:125-132

31. Volpe JJ 2001 Neurology of the Newborn. W.B. Saunders Company, Philadelphia, pp 201-202

32. Bittigau P, Sifringer M, Genz K, Reith E, Pospischil D, Govindarajalu S, Dzietko M, Pesditschek S, Mai I, Dikranian K, Olney JW, Ikonomidou C 2002 Antiepileptic drugs and apoptotic neurodegeneration in the developing brain. Proc Natl Acad Sci U S A 99:15089-15094

33. Holmes GL 2002 Seizure-induced neuronal injury-animal data. Neurology 59:S3-S6

34. Huang LT, Cilio MR, Silveira DC, McCabe BK, Sogawa Y, Stafstrom CE, Holmes GL 1999 Long-term effects of neonatal seizures: a behavioral, electrophysiological, and histological study. Dev Brain Res 118:99-107

35. Young RS, Osbakken MD, Briggs RW, Yagel SK, Rice DW, Goldberg S 1985 31P NMR study of cerebral metabolism during prolonged seizures in the neonatal dog. Ann Neurol 18:14-20

36. Miller SP, Weiss J, Barnwell A, Ferriero DM, Latal-Hajnal B, Ferrer-Rogers A, Newton N, Partridge JC, Glidden DV, Vigneron DB, Barkovich AJ 2002 Seizure-associated brain injury in term newborns with perinatal asphyxia. Neurology 58:542-548

37. Klebermass K, Kuhle S, Kohlhauser-Vollmuth C, Pollak A, Weninger M 2001 Evaluation of the cerebral function monitor as a tool for neurophysiological surveillance in neonatal intensive care patients. Childs Nerv Syst 17:544-550

38. Murdoch-Eaton D, Toet M, Livingston J, Smith I, Levene M 1994 Evaluation of the Cerebro Trac 2500 for monitoring of cerebral function in the neonatal intensive care. Neuropediatrics 25:122-128 